\title{
Editorial
}

\section{Empowering Women Nurses Can Make a Difference}

\author{
Ibtisam K. Ghrayeb, RN, BSN, PGD'; Michael Silbermann, DMD, PhD²* \\ 'Pediatric Intensive Care Unit, Makassad Hospital, Bethlehem, Palestine \\ ${ }^{2}$ Middle East Cancer Consortium, Haifa, Israel
}

*Corresponding author

Michael Silbermann, DMD, PhD

Executive Director, Middle East Cancer Consortium, 45 Yotam Street, Haifa 34675, Israel; E-mail: cancer@mecc-research.com

\section{Article information}

Received: March 5th 2018; Accepted: March 6 $6^{\text {th }}$, 2018; Published: March 6 $6^{\text {th }}, 2018$

\section{Cite this article}

Ghrayeb IK, Silbermann M. Empowering women nurses can make a difference. Palliat Med Hosp Care Open J. 20I8; 4(I): el-e2. doi: I0.17।40/PMHCOJ-4-e006

\section{ABSTRACT |}

Women play an important role in the advancement of science, medicine, and health. The issue of gender is still a debatable item in many cultures and societies. However, despite remarkable advances in gender equality, there are still disturbing barriers that need to be broken down in order to reach the desired goal. The empowerment of female nurses has created status changes and improvements in cancer care. Whereas marked achievements have been noted in developed countries, much work is still needed in developing countries, where culture and tradition hinder this process.

\section{Keywords}

Cancer care; Women nurses; Empowerment.

W omen are integral to health promotion and academic excellence. To date, women have been faced with ongoing challenges in achieving their goals clinically and scientifically. In order to try to overcome some of such challenges, dedicated strategies are needed to support the advancement of women socially, professionally and health wise. Such an approach needs local, regional and global advocacy to support women in their efforts to be fully integrated into modern medical and scientific societies. ${ }^{1}$

A survey in Australia checked the health promotion role of doctors in a women's and community health centers and in private practices. It was found that doctors within women's and community health centers are more likely to report involvement in group health promotion activity and broader community development initiatives. ${ }^{2}$

The Middle East Cancer Consortium (MECC), as a regional organization of individuals, clinical and academic institutions had a unique opportunity to promote the role of gender in health. We have found that there is no tool for development more effective than the empowerment of women. Moreover, we feel that no policy is more important in reducing conflict or in achieving reconciliation. A study in Nepal concluded that the empowerment of female community health volunteers will bring sustainable change in women's performance and will consequently produce notable improvement in the health of women and children, in particular, and in the community, in general. ${ }^{3}$ It is clear that at least in developing countries, there are social and cultural barriers that hinder the empowerment of women. Women's low status, deprivation of education and lack of control over their own lives and bodies have a negative impact on their professional development be it in medicine or science. A study in Pakistan indicated that to improve women's professional career, a concerted action is needed by the family, community, healthcare systems and the state in order to achieve gender equality and the greater empowerment of women. ${ }^{4}$ Further, domestic violence and poverty were identified as additional stress factors that hinder the empowerment of women in India. ${ }^{5} \mathrm{~A}$ more recent study in Iran indicated the importance of women's empowerment through foraging their health information seeking rights and comprehensive health information adherence. ${ }^{6}$ It is our strong belief that advocating for women will undoubtedly contribute to the improvement of both women's own health and their active involvement in the promotion of health (clinically and scientifically) worldwide.

For nurses to advance in their profession, one should be able to lead the nursing profession in a positive light without restrictions related to gender. Female nurses are often not empowered to break the traditional culture of silence and more women than men work part-time. ${ }^{7}$ 
In healthcare people have a real opportunity to make a difference in people's lives, and women nurses often use critical thinking skills, initiate lifesaving measures, evaluate and effectively monitor their patients. Further, they listen and counsel the patient and his/ her family and extend important emotional support. Yet, women empowerment can be achieved only when they gain the proper education and are financially independent. Also, the work of the female nurse as manager strengthens the teamwork, which improves the team's image thereby contributing to its identity. Therefore, without the empowerment of women and gender equality, it is impossible to obtain sustainable growth globally. Promoting women in the health sector, generally, and in nursing, in particular, induces essential creativity and a real change in the nurses' mission. It is therefore highly recommended that female nurses are equally represented in all levels of policy making, in decision making positions, while ensuring no gender bias.

\section{CONFLICTS OF INTEREST}

The authors declare no conflicts of interest.

\section{DISCLOSURES |}

Both authors contributed equally to the writing of this Editorial.

\section{REFERENCES}

1. Bauman MD, Howell LP, Villablanca AC. The women inmedicine and health science program: An innovative initiative to support female faculty at the University of California Davis School of Medicine. Acad Med. 2014; 89: 1462-1466. doi: 10.1097/ ACM.0000000000000403

2. Baum F, Kalucy E, Lawless A, Barton S, Steven I. Health promotion in different medical settings: Women's health, community health and private practice. Aust N Z J Public Health. 1998; 22: 200205. doi: 10.1111/j.1467-842X.1998.tb01172.x

3. Shrestha S. A conceptual model for empowerment of the female community health volunteers in Nepal. Educ Health (Abingdon). 2003; 16: 318-327.

4. Qureshi N, Shaikh BT. Women's empowerment and health: The role of institutions of power in Pakistan. Eastern Mediterranean Health Journal. 2007; 13: 1459-1465.

5. Kermode M, Herrman H, Arole RF, White J, Premkumar R, Patel V. Empowerment of women and mental Health promotion: A qualitative study in rural Maharashtra, India. BMC Public Health. 2007; 7: 225-235. doi: 10.1186/1471-2458-7-225

6. Nasrabadi AN, Sabzevari S, Bonabi TN. Women empowerment through health information seeking? A qualitative study. Int J Community Based Nurs Midwifery. 2015; 3: 105-115.

7. Tlou SD. Women and health: Mainstreaming the gender perspective in health care, including the management of human and financial resources in nursing. Garbone, Botswana: University of Botswana; 2018. Web site. http://www.un.org/womenwatch/ daw/csw/nursing.htm. Accessed March 4, 2017. 